\title{
What is a Successful Digital Library?
}

\section{ECDL 2006, Alicante, September 18, 2006}

Rao Shen, Naga Srinivas Vemuri, Weiguo Fan, and Edward A. Fox

fox@vt.edu http://fox.cs.vt.edu 


\section{Acknowledgements (Selected)}

- Sponsors: NSF grant ITR-0325579, ASOR, CWRU, ETANA, Vanderbilt U., Virginia Tech

- Faculty/Staff: Lillian Cassel, Debra Dudley, Manuel Perez, ...

- VT (Former) Students: Aaron Krowne, Ming Luo, Fernando Das Neves, Ricardo Torres, Hussein Suleman, ... 


\section{Acknowledgements (Selected)}

- Karen Borstad, MPP

- Giorgio Buccellati, UCLA

- Douglas Clark, Walla Walla College

- Joanne Eustis, CWRU

- Nick Fischio, CWRU

- Israel Finkelstein, Tel-Aviv University

- Paul Gherman, Vanderbilt U.

- Andrew Graham, U. Toronto

- Tim Harrison, U. Toronto

- Larry Herr, Canadian University College
- Christopher Holland, LRP

- Paul Jacobs, Mississippi State U.

- Douglas Knight, Vanderbilt U.

- Stan LaBianca, Andrews U.

- David McCreery, Willamette U.

- Eric Meyers, Duke U.

- Adam Porter, Illinois College

- Jack Sasson, Vanderbilt U.

- Tom Schaub, Indiana U. of Penn.

- Randall Younker, Andrews U. 


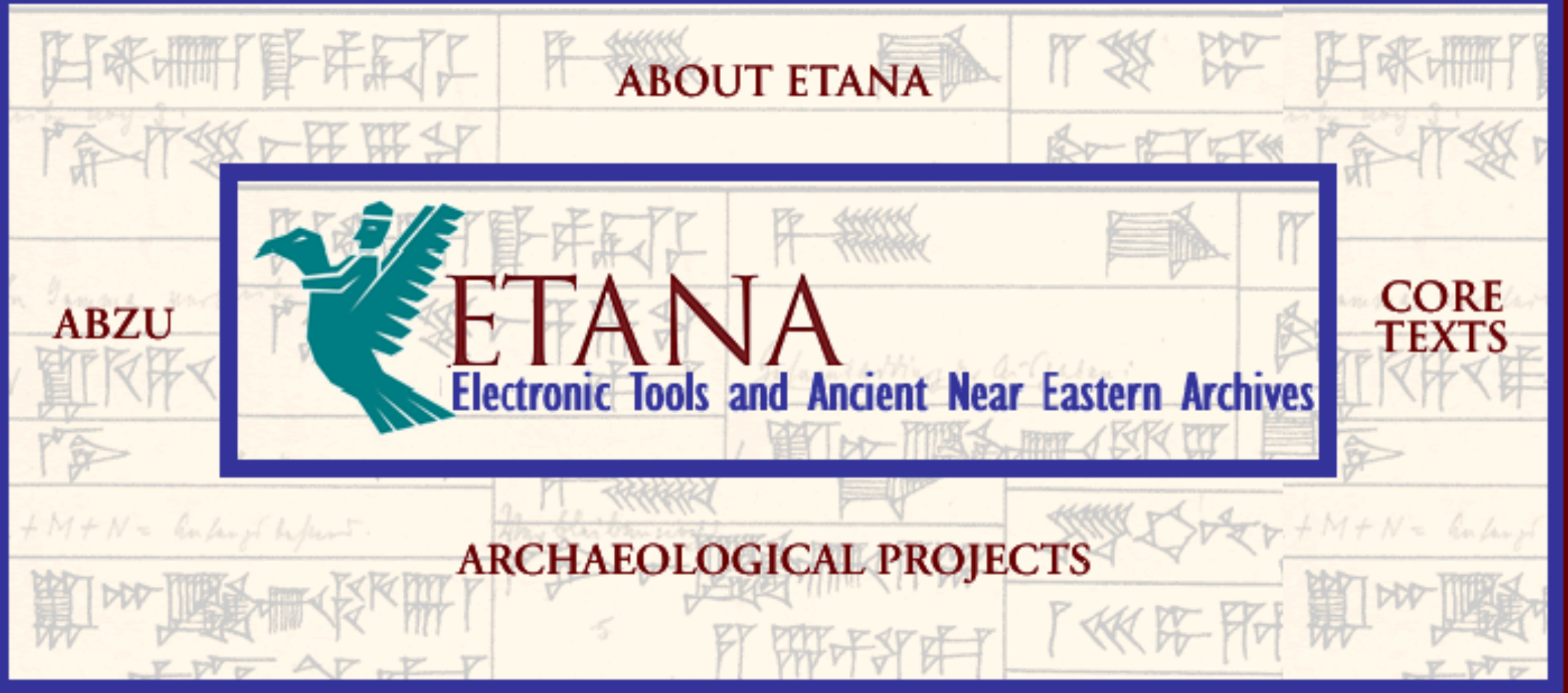

Copyright 2003 ETANA

ETANA is a cooperative project of:

American Oriental Society | American Schools of Oriental Research | Case Western Reserve University

Cobb Institure of Archaeology at Mississippi State | Oriental Institute of the University of Chicago I Society of Eiblical Literature Sonia and Marco Nadler Institute of Archaeology of Tel Aviv University | Vanderbilt University I Virginia Polytechnic and State University

Support for ETANA has been provided by funding from the Andew W. Mellon Foundation ( 800 to 202 , 601 to 802 ) and the National Science Foundation (Continuing grant //S-0325579) 


\section{ETANA-DL Website}

ETANA-DL

Managing complex information applications:

Visual Browse I Browse Collections I Help

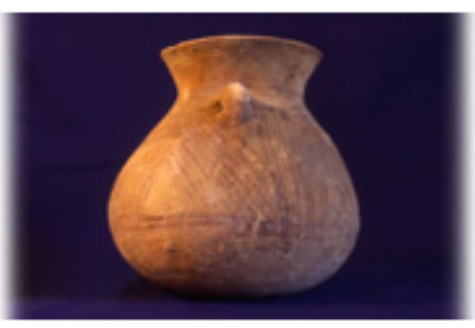

Want to know more about our collections? Click here

Your comments, suggestions and feedback are important to us! Let us know what you think.

\section{Welcome to ETANA-DL}

This research proposes to develop a digital library (DL) for ancient Near Eastern studies with two archaeological components: DigBase (DB) - a repository and an archive for archaeological data from the Near East and beyond, and DigKit (DK) - a compatible field tool for collecting and recording archaeological data during archaeological surveys and excavations. DB is a model-based, extensible, archaeological componentized DL that will manage complex archaeological information sources based on the client-server paradigm of the Open Archives Initiative Protocol for Metadata Harvesting (OAI-PMH). DK is a compatible field tool for collecting, recording and exposing archaeological data in an $\mathrm{OAI}$ compliant manner during archaeological surveys and excavations.

If this is the first time you are visiting the Digital Library, you might want to go thru the short tutorial.

\section{Recent Discussions}

$8 / 23 / 05$ - horse of fiqurine by rshenovt.edu

12/3/04 - Re: test by unni@vt.edu

12/3/04 - test by unniout.edu

\section{Home About ETANA CWRU Vanderbilt}

This project is funded in part by National Science Foundation's ITR program 


\section{ETANA-DL's Member Collections}

\begin{tabular}{|c|c|c|c|}
\hline Site & Artifact Type & Original data source & Number of records harvested \\
\hline Bab edh-Dhra' & Pottery & cp6 database file & 7965 \\
\hline Lahav & Figurine & Tab-delimited text file & 563 \\
\hline Madaba & Locus field record & Tables in Access DB & 789 \\
\hline \multirow{4}{*}{ Megiddo } & Flint & Tables in Access DB & 4292 \\
\cline { 2 - 4 } & Lab item & Tables in Access DB & 11328 \\
\cline { 2 - 4 } & Locus field record & Tables in Access DB & 2163 \\
\cline { 2 - 4 } & Miscellaneous artifact & Tables in Access DB & 2453 \\
\cline { 2 - 4 } & Pottery bucket & Tables in Access DB & 9200 \\
\cline { 2 - 4 } & Vessel & Tables in Access DB & 1307 \\
\cline { 2 - 4 } & Wall & Tables in Access DB & 455 \\
\hline \multirow{3}{*}{ Mozan } & Publication & PDF files & 19 \\
\hline \multirow{3}{*}{ Umayin } & Bone field record & Tables in Oracle DB & 7419 \\
\cline { 2 - 4 } & Seed field record & Tables in Oracle DB & 429 \\
\cline { 2 - 4 } & Locus field record & Tables in Oracle DB & 2102 \\
\hline \multicolumn{2}{|c|}{ Bone field record } & Tables in Access DB & 2122 \\
\hline
\end{tabular}




\section{Outline}

$>$ Prior work

$>$ DL success model

- From end user perspective

$>$ Case study

$>$ Conclusion 


\section{Prior Work on Measuring DL Success}

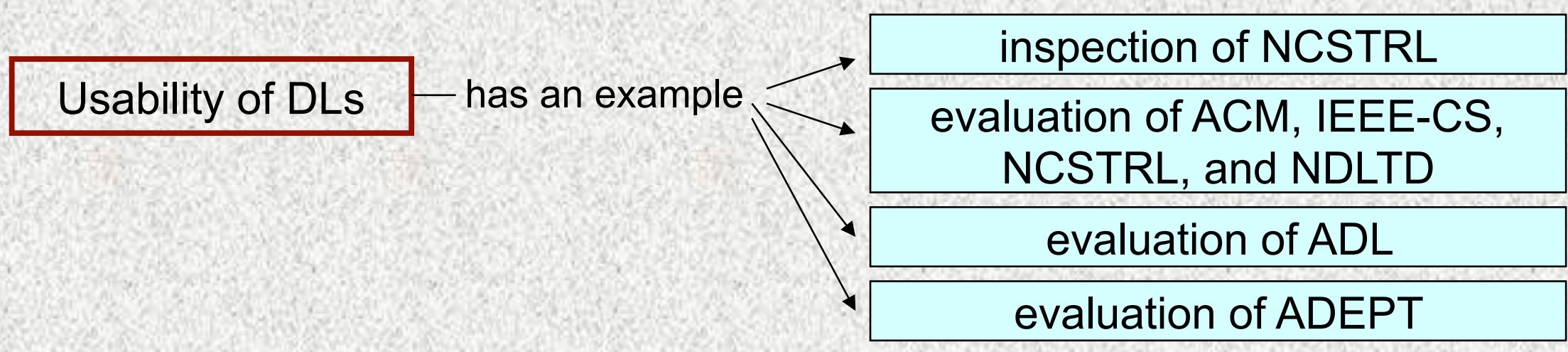

\begin{tabular}{|c|c|}
\hline $\begin{array}{c}\text { Technology } \\
\text { acceptance model }\end{array}$ & predict $\longrightarrow$ has an example $\longrightarrow$ Intention to re/use \\
\hline
\end{tabular}

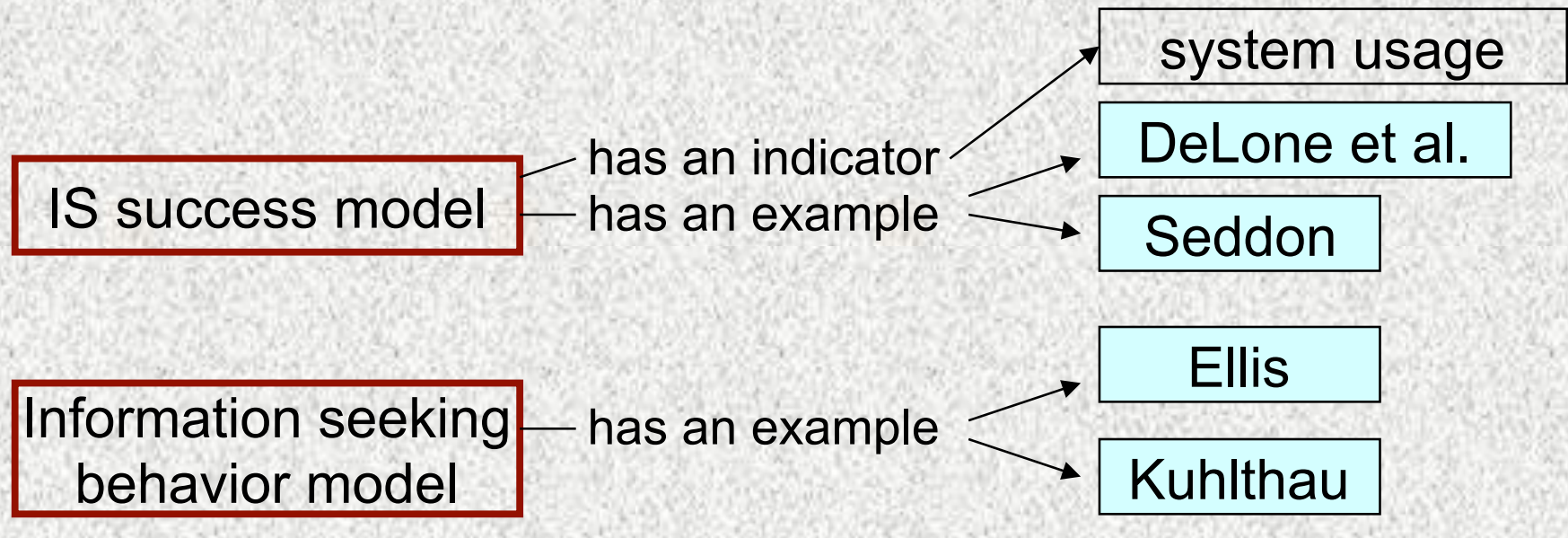

DL quality model - has an example $\longrightarrow$ Gonçalves 


\section{Behavioral Attitude \& Intension to Use - Venkatesh Model of IT Adoption}

Unified Theory of Acceptance and Use of Technology performance expectancy

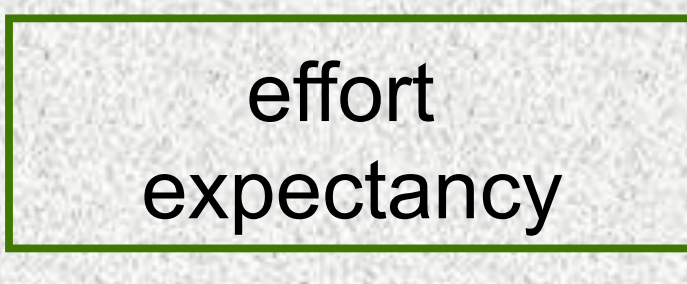

social influence

facilitating conditions

system usage 


\section{Venkatesh Model of IT Adoption}

- Performance expectancy:

- perceived usefulness, extrinsic motivation, job-fit, relative advantage, and outcome expectations

- Effort expectancy

- the degree of ease associated with the use of system

- Social influence

- Subjective norms, social factors, and image

- Facilitating conditions

- the degree to which an individual believes that an organizational and technical infrastructure exist to support the system 


\section{DeLone and McLean Model of IS Success}

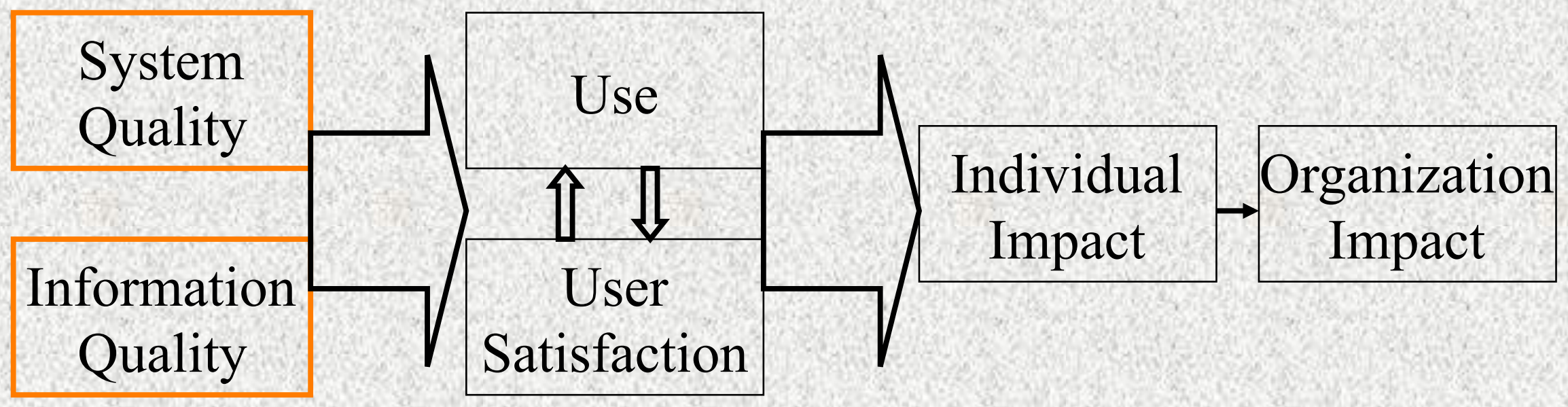




\section{Seddon Model of IS Success}

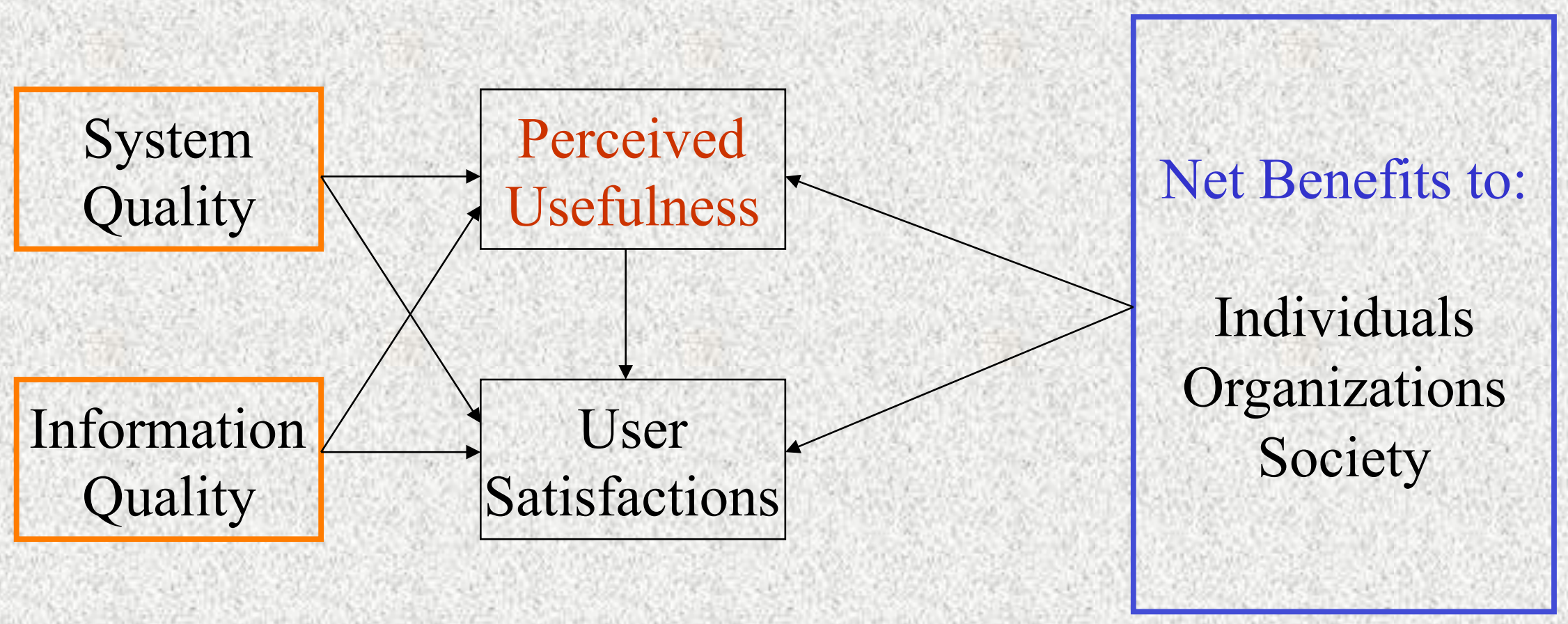




\section{Outline}

$>$ Prior work

$>$ DL success model

- From end user perspective

$>$ Case study

$>$ Conclusion 


\section{Success Model}

$>5 S$ and minimal DL

$>$ Synthesize

- IS success and adoption models (see above)

- Information life cycle model (Borgman et al.)

- 5S-based DL quality model (Gonçalves et al.)

- Information-seeking behavior models (Ellis' and Kuhlthau's)

$>$ From end user perspective 


\section{Informal 5S \& DL Definitions}

DLs are complex systems that

- help satisfy info needs of users (societies)

- provide info services (scenarios)

- organize info in usable ways (structures)

- present info in usable ways (spaces)

- communicate info with users (streams) 


\section{S and DL formal definitions and compositions (April 2004 TOIS)}

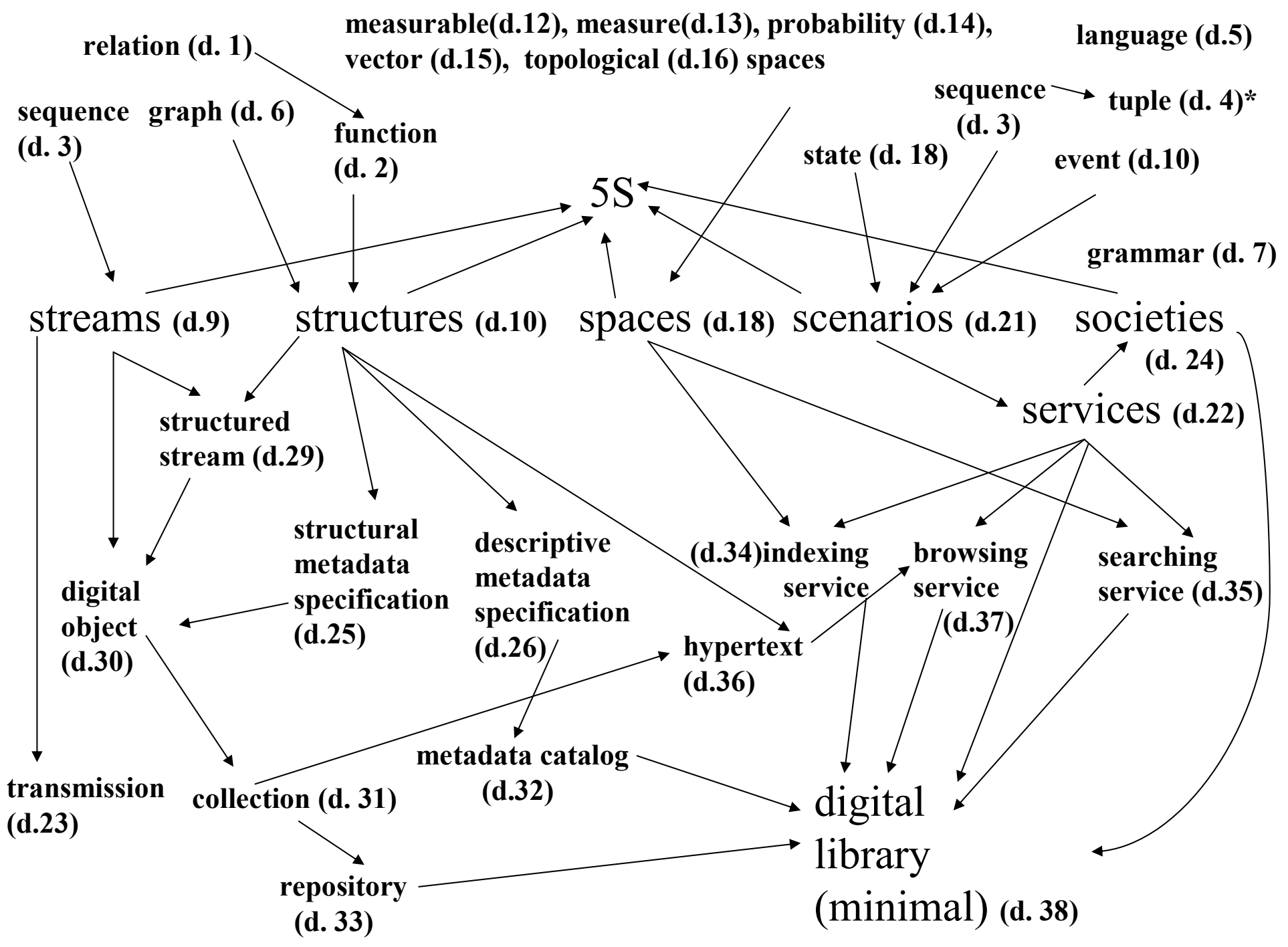




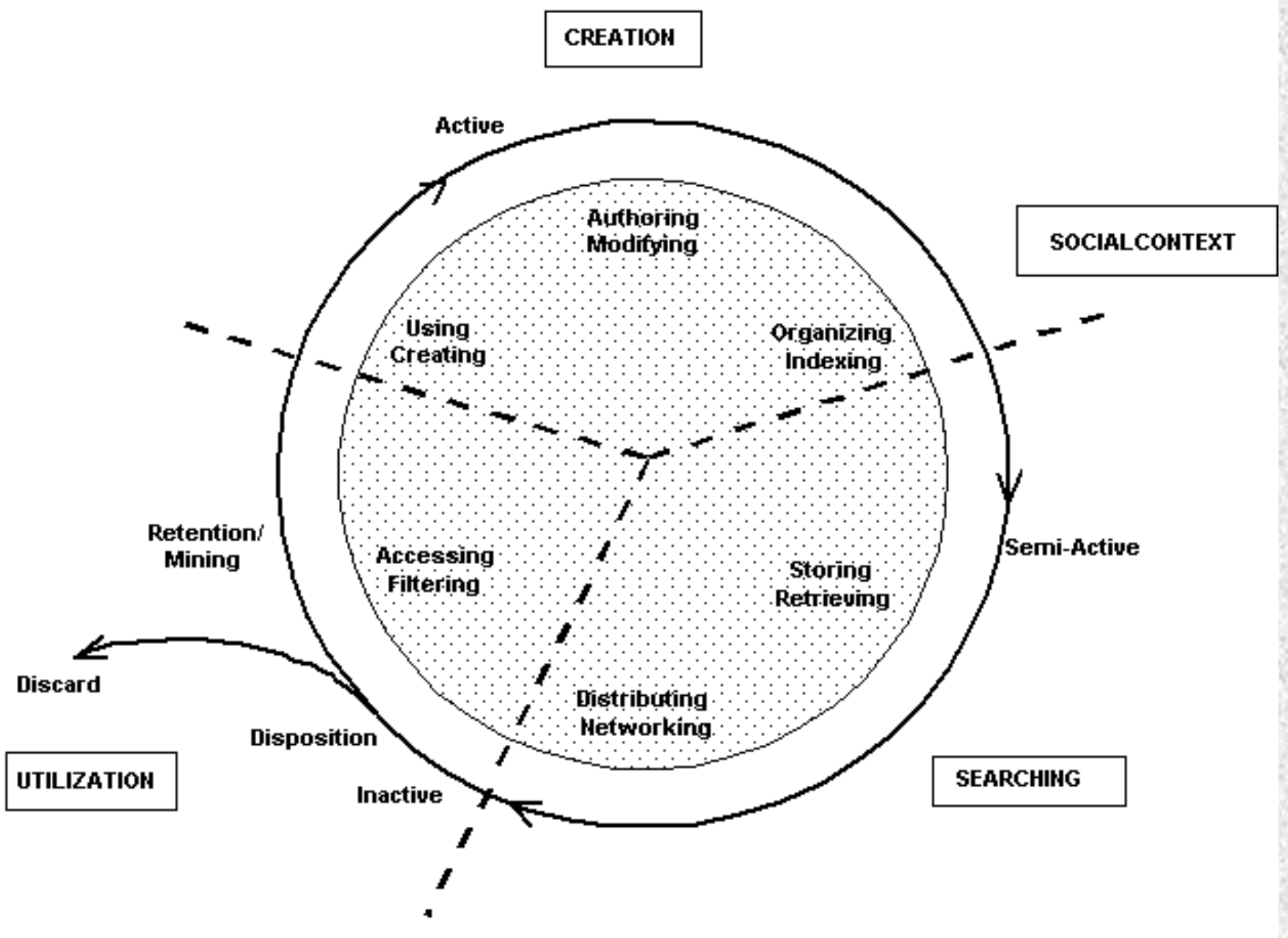

NOTE: The outer ring indicates the life cycle stages (active, serni-active, and inactive) for a given type of information artifact (such as business records, artworks, documents, or scientific data). The stages are superimposed on six types of information uses or processes (shaded circle). The cycle has three major phases: information creation, searching, and utilization. The alignment of the cycle stages with the steps of information handling and process phases may vary according to the particular social or institutional context.

\section{Information}

Life

Cycle

Borgman et al: :

Workshop Report on Social Aspects of Digital Libraries: http://www-lis.gseis. ucla.edu/DL/ 


\section{Information Life Cycle}

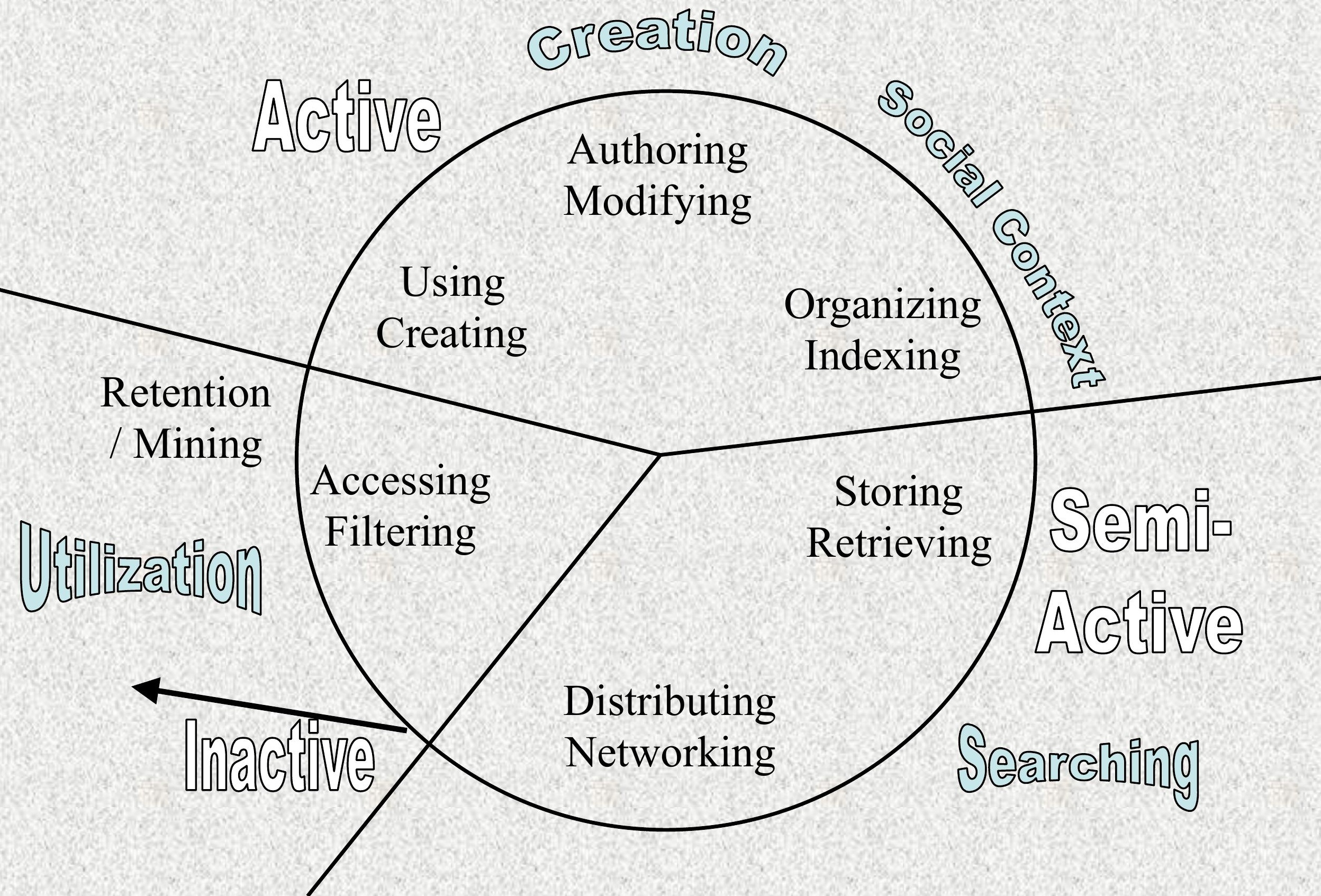




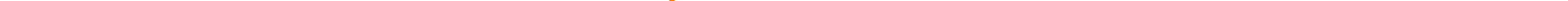




\begin{tabular}{|c|c|c|c|}
\hline $\begin{array}{l}\text { DL quality } \\
\text { dimension }\end{array}$ & $\begin{array}{c}\text { DL success } \\
\text { manifest variable }\end{array}$ & $\begin{array}{c}5 S \text { and } \\
\text { DL concept }\end{array}$ & DL success construct \\
\hline $\begin{array}{c}\text { accessibility } \\
\text { accuracy } \\
\text { completeness } \\
\text { consistence } \\
\text { conformance } \\
\text { pertinence } \\
\text { preservability } \\
\text { relevance } \\
\text { significance } \\
\text { similarity } \\
\text { timeliness }\end{array}$ & $\begin{array}{c}\text { adequacy } \\
\text { relevance } \\
\text { reliability } \\
\text { scope } \\
\text { timeliness } \\
\text { understandability }\end{array}$ & $\begin{array}{c}\text { stream, structure } \\
\text { digital object } \\
\text { metadata } \\
\text { collection } \\
\text { catalog } \\
\text { repository }\end{array}$ & information quality (IQ) \\
\hline $\begin{array}{c}\text { composability } \\
\text { efficiency } \\
\text { effectiveness } \\
\text { extensibility } \\
\text { reusability } \\
\text { reliability }\end{array}$ & $\begin{array}{c}\text { accessibility } \\
\text { reliability } \\
\text { ease of use } \\
\text { joy of use }\end{array}$ & $\begin{array}{c}\text { society, scenario, } \\
\text { space } \\
\text { service }\end{array}$ & $\begin{array}{c}\text { system quality (SQ) } \\
\text { performance expectancy (PE) }\end{array}$ \\
\hline & DL visibility & society & social influence (SI) \\
\hline
\end{tabular}




\section{E: Ellis' model}

K: Kuhlthau's model col completeness,

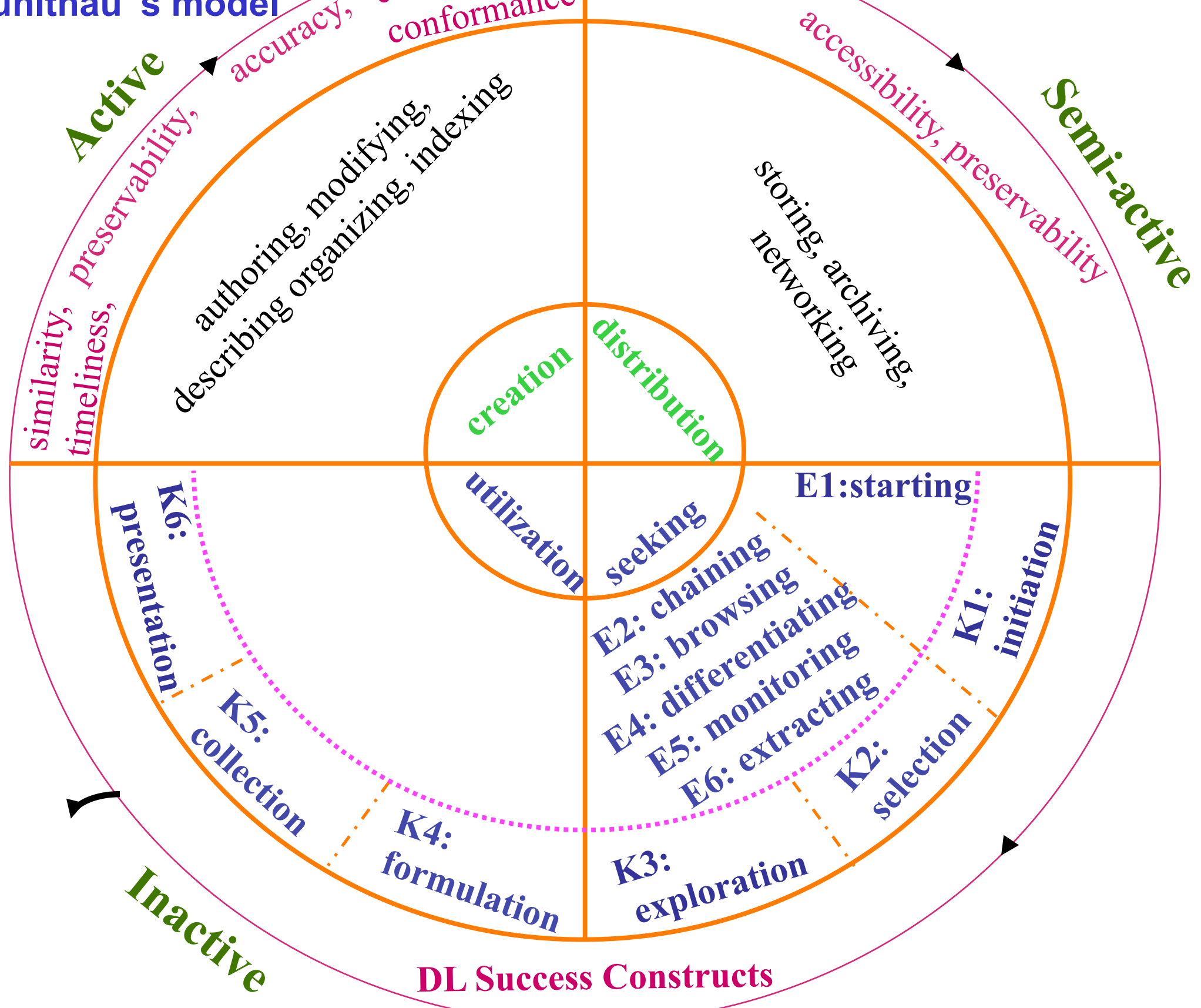




\section{Success Model}

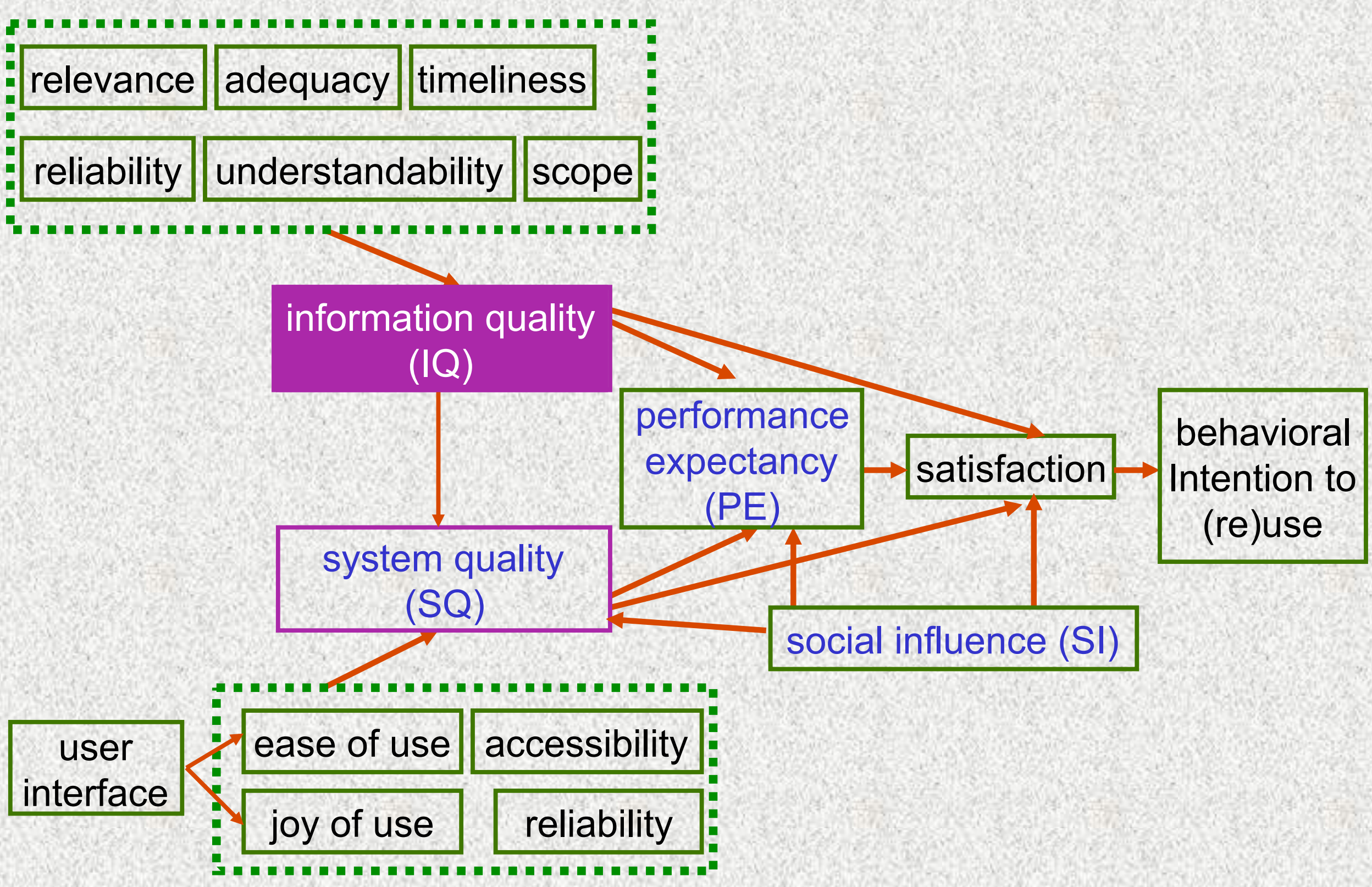




\section{Concepts Regarding Information}

associated with

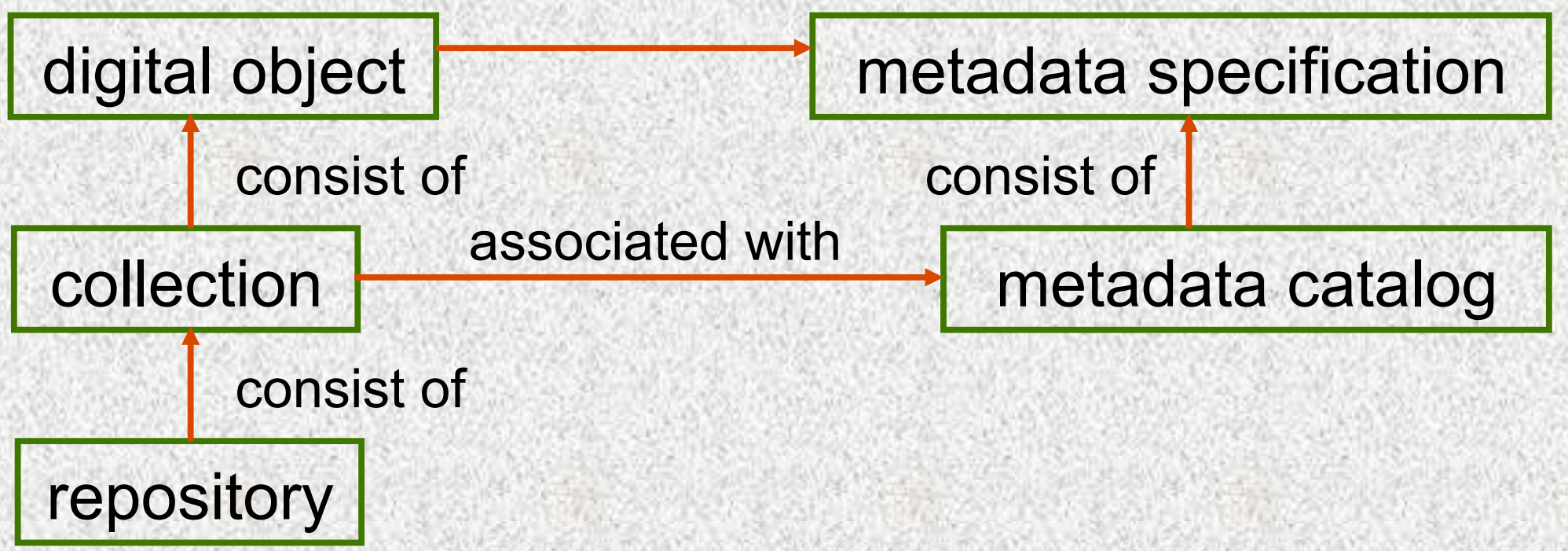




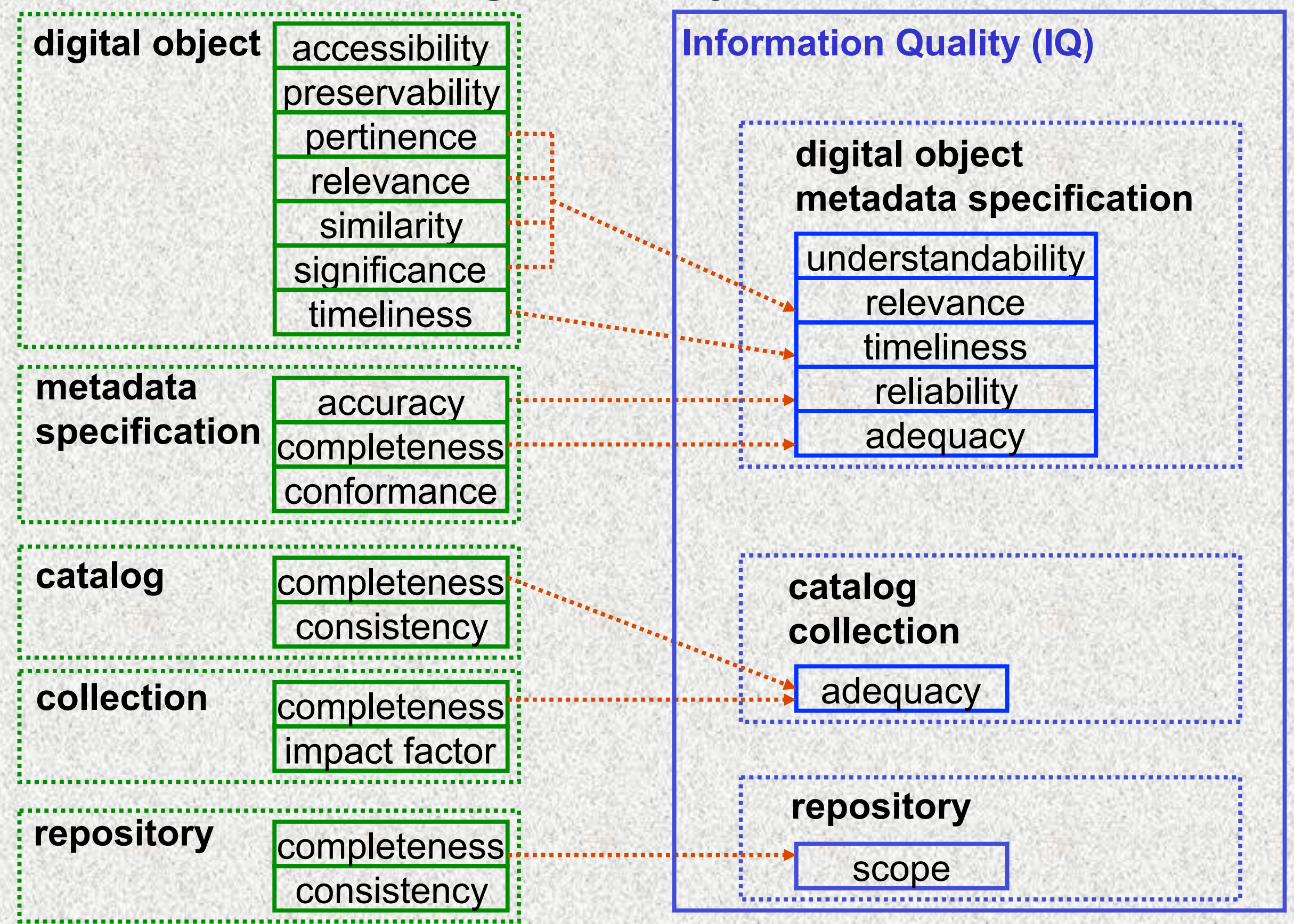




\section{Success Model}

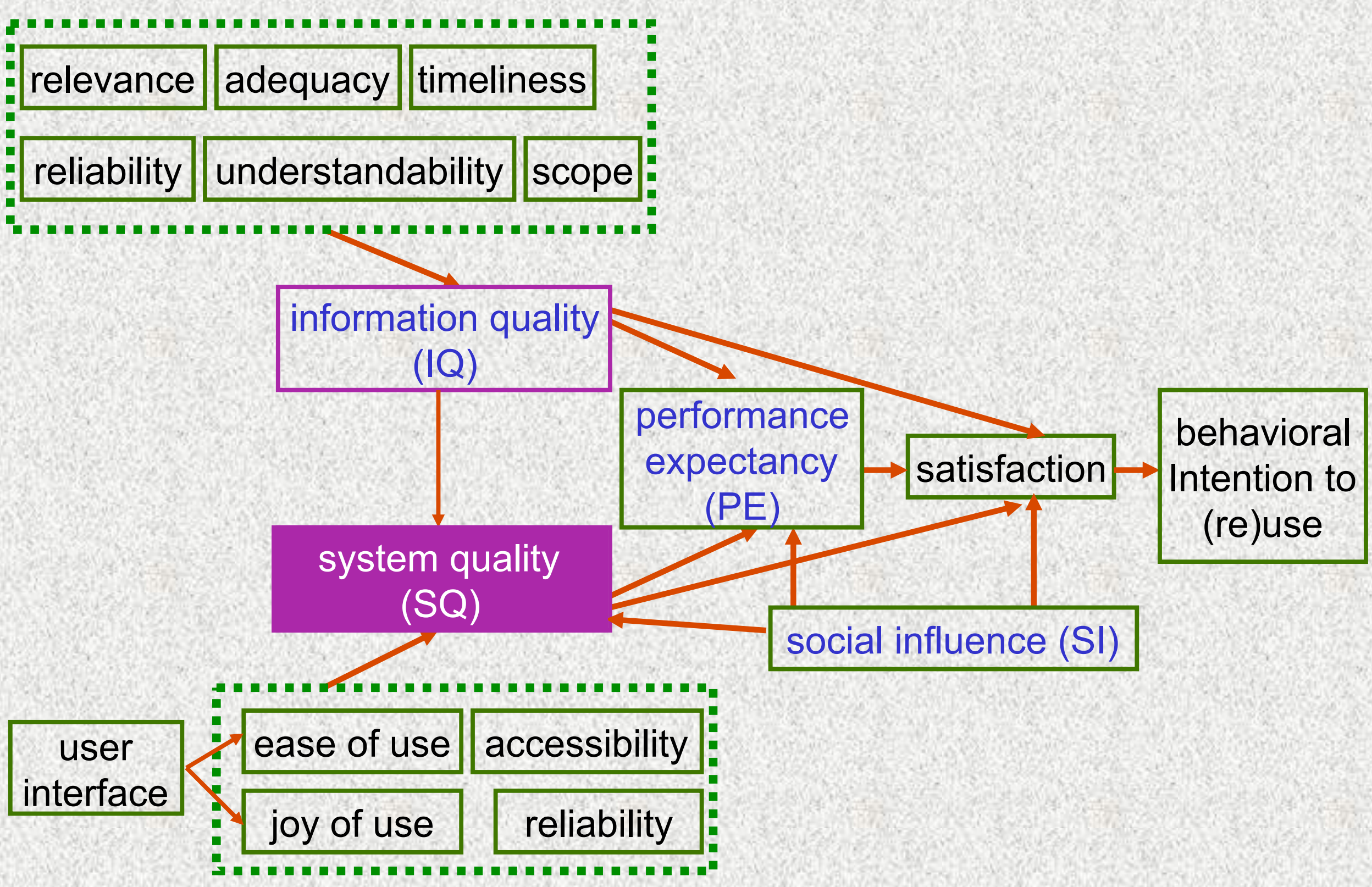




\section{Outline}

$>$ Prior work

$>$ DL success model

- From end user perspective

$>$ Case study

$>$ Conclusion 


\section{Case Study}

$>$ Part of requirements analysis for ETANA-DL

- Email interviews with 5 prestigious archaeologists

- Face to face workplace interviews with 11 archaeologists

$>$ Associate the 4 constructs of DL success model with the activities occurring in the seeking and utilization phases 


\section{Success Constructs Associated with Seeking and Utilization Phases}

\begin{tabular}{|c|c|c|c|c|c|}
\hline \multirow{2}{*}{$\begin{array}{c}\text { DL success } \\
\text { Construct }\end{array}$} & \multicolumn{2}{|c|}{ seeking phase } & \multicolumn{3}{|c|}{ utilization phase } \\
\hline & $\begin{array}{l}\text { starting } \\
\text { (E1/K1) }\end{array}$ & $\begin{array}{c}\text { selection } \\
\text { exploration } \\
(E 2-E 6) /(K 2-K 3)\end{array}$ & $\begin{array}{l}\text { formulation } \\
\text { (K4) }\end{array}$ & $\begin{array}{l}\text { collection } \\
\text { (K5) }\end{array}$ & $\begin{array}{l}\text { presentation } \\
\text { (K6) }\end{array}$ \\
\hline social influence & $\begin{array}{c}D L \\
\text { visibility }\end{array}$ & & & & \\
\hline information quality & & adequacy, scope & accuracy & & \\
\hline system quality & & $\begin{array}{l}\text { ease of use } \\
\text { joy of use } \\
\text { (interface) }\end{array}$ & accessibility & accessibility & accessibility \\
\hline $\begin{array}{c}\text { performance } \\
\text { expectancy }\end{array}$ & & $\begin{array}{l}\text { usefulness } \\
\text { (interface) }\end{array}$ & & & \\
\hline
\end{tabular}


DL Success Constructs Associated with Seeking Phase

$>$ E1: Starting' activity in Ellis' model (K1: 'initiation' stage in Kuhlthau's model)

- Social Influence (SI) - DL visibility

$\star$ Publicize existence of a DL

*Provide a DL alert service 
DL Success Constructs Associated with Seeking Phase

> E2-E6: 'chaining', 'browsing', 'differentiating', 'monitoring', and 'extracting' in Ellis' model (K2-K3:

'selection' and 'exploration' stages in Kuhlthau's model)

- Information Quality (IQ)

- System Quality (SQ)

- Performance Expectancy (PE) 
DL Success Constructs Associated with Seeking Phase

>E2-E6: 'chaining', 'browsing', 'differentiating', 'monitoring', and 'extracting' in Ellis' model (K2-K3: 'selection' and 'exploration' stages in Kuhlthau's model)

- Information Quality (IQ)

- Adequacy (degree of sufficiency and completeness) of $\mathrm{DL}$ collections and metadata catalogs

* Scope of DL repository 
DL Success Constructs Associated with Seeking Phases

> E2-E6: 'chaining', 'browsing', 'differentiating', 'monitoring', and 'extracting' in Ellis' model (K2-K3:

'selection' and 'exploration' stages in Kuhlthau's model)

- System Quality (SQ)

- Ease of use

* Joy of use 
DL Success Constructs Associated with Seeking Phases

> E2-E6: 'chaining', 'browsing', 'differentiating', 'monitoring', and 'extracting' in Ellis' model (K2-K3:

'selection' and 'exploration' stages in Kuhlthau's model)

- Performance Expectancy (PE)

* Usefulness 
DL Success Constructs Associated with Seeking Phases

> E2-E6: 'chaining', 'browsing', 'differentiating', 'monitoring', and 'extracting' in Ellis' model (K2-K3: 'selection' and 'exploration' stages in Kuhlthau's model)

- System Quality \& Performance Expectancy - DL interface: screen design \& navigation 
DL Success Constructs Associated with Utilization Phase

$>$ K4-K6: 'formulation', 'collection', and 'presentation' stage in Kuhlthau's model

- Information Quality

* information accuracy

* information accessibility 


\section{Outline}

$>$ Prior work

$>$ DL success model

- From end user perspective

$>$ Case study

$>$ Conclusion 


\section{Conclusion}

$>$ Lay the foundation for defining success of DLs from the view of DL end users

$>$ Assume a multi-theoretical perspective

$>$ Synthesize many related research areas in terms of theory and empirical work

$>$ Explicate and illustrate our approach by a case study with ETANA and usability

$>$ Connect with other work on DL quality: led by Emory funded by IMLS, DELOS ... 


\section{Questions? \\ Comments?}

See http://fox.cs.vt.edu/talks/2006/ 20060918ECDLsuccess.ppt

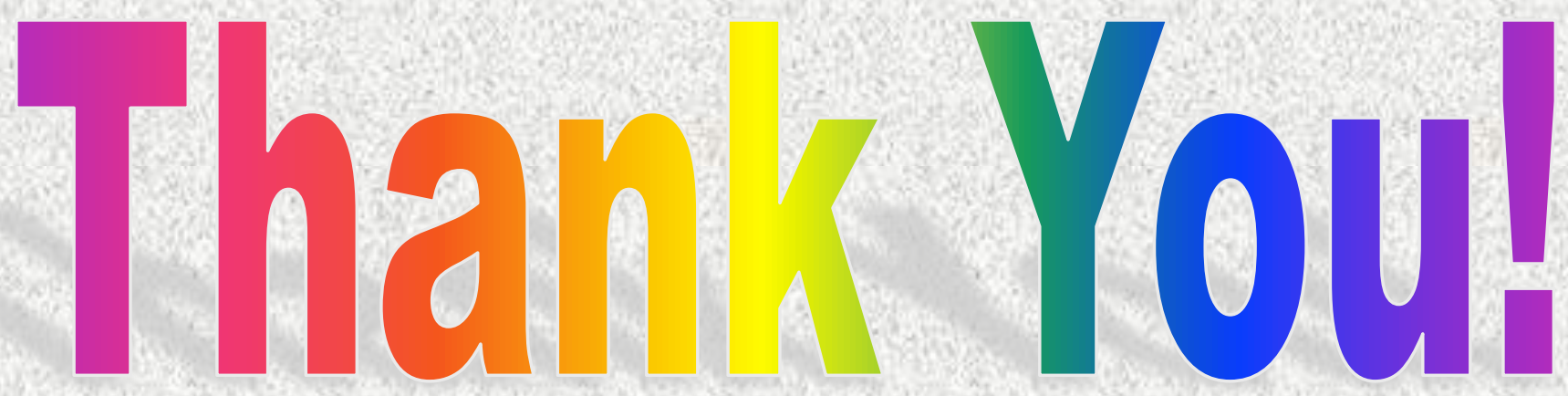

